\title{
論文
}

\author{
트리거 모델에 따른 일방향 케블라/에폭시 복합재 튜브의 \\ 축방향 압괴 거동 연구 \\ 김형욱 ${ }^{*+}$, 김정석**, 정현승 ${ }^{* *}$, 윤혁진 ${ }^{* *}$, 권태수 ${ }^{* *}$
}

\section{Study on Axial Cnushing Behaviors of UD Kevlar/Epoxy with Different Trigger Models}

\author{
Hyung-Uk Kim $^{*+}$, Jung-Seok Kim ${ }^{* *}$, Hyun-Seung Jung ${ }^{* *}$, Hyuk-Jin Yoon ${ }^{* *}$, and Tae-Soo Kwon ${ }^{* * *}$
}

\begin{abstract}
In this paper, in order to develop a realistic trigger model for a unidirectional Kevlar/Epoxy tube, the numerical model has been established and then verified by comparison with the experimental result. To achieve this goal, four different trigger models were candidated and evaluated using the commercial explicit FE code LS-DYNA. In the finite element analysis, the 2D shell element and Chang-Chang failure criterion was used. Mechanical material properties for the model were obtained by material testing in advance. The numerical results were compared with quasi-static test results under axial compressive loading at $10 \mathrm{~mm} / \mathrm{min}$. The load-crushed displacement curves were very close to the experiments and SEA (specific energy absorption) showed a good agreement with experimental one within less than $5 \%$.

\section{초 록}

본 논문에서는 일방향 케블라/에폭시 튜브에 대한 현실적인 트리거 모델링을 개발하기 위해 수치해석 모델이 확립하고 시 험결과와 비교를 통해 검증하였다. 이를 위해, 4 가지 트리거 모델을 제안하고 각각에 대해 상용 외연적 해석 프로그램인 LS-DYNA을 이용하여 유한요소 해석을 통해 축방향 압괴특성을 규명하였다. 유한요소해석에서는 2D 쉘요소와 Chang-Chang 파손기준식을 이용하였다. 또한, 해석에 적용된 소재의 기계적 물성치는 시험을 통해 얻었다. 해석모델은 원형 튜브에 대한 $10 \mathrm{~mm} / \mathrm{min}$ 의 준정적 압괴시험결과와 비교를 통해 검증하였다. 그 결과 케블라/에폭시 튜브의 하중-변위 곡선은 거의 일치했으 며 무게당 흡수 에너지 (SEA)도 5\% 미만의 오차에서 잘 일치하였다.
\end{abstract}

Key Words : 복합재료(composite material), 케블라(kevlar), 트리거(trigger), 튜브(tube)

\section{1. 서 론}

\section{1 연구의 배경}

충돌사고로부터 승객과 운전자의 안전을 지키는 방법은 크 게 두 가지로 나눌 수 있다. 사고를 미연에 방지하는 능동적
안전 (active safety)과 미처 사고를 막지 못했을 때 피해를 최 소화시키는 수동적 안전 (passive safety)에 의한 방법이다. 여 기서 수동적 안전은 안전을 확보하기 위한 최후의 수단으로 팽창튜브, 좌굴튜브, 허니콤, 버퍼 등의 에너지 흡수부재가 개 발되어 사용되고 있다. 하지만 최근 운송수단들의 고속화, 고

\footnotetext{
*+ 과학기술연합대학원대학교 가상공학과, 교신저자(E-mail:hukim@ust.ac.kr)

** 한국철도기술연구원 철도구조연구실

*** 한국철도기술연구원 정책전략연구실
} 
효율화가 진행되면서 이러한 에너지 흡수부재들은 경량화 측 면에서 문제를 가지게 된다.

\section{2 연구의 동향 및 목적}

복합재료는 금속재에 비해 가벼운 중량과 에너지 흡수 성능 이 뛰어나 1990년 후반부터 우주/항공[1], 자동차[2], 선박 등 의 에너지흡수 부재와 구조물로 널리 적용되고 있지만 금속 재료와 다르게 소성거동을 거의 보이지 않으며, 섬유 및 수지 의 파단, 섬유/수지 분리, 층간분리, 섬유의 미소좌굴 같은 특 이한 파손 메커니즘을 가지고 있어서 유한요소법을 이용하여 에너지 흡수특성과 붕괴모드를 예측하기 어려운 것으로 알려 져 있다. 파손 메카니즘 외에도 트리거 (tigger)는 중요한 인자 로 최대하중 및 압괴거동을 결정한다. 이러한 트리거는 쉘 요 소로 정밀하게 모델링하기 어려워 Huang 등[3]은 트리거를 여 러 단계로 나누어 다층 (multi layer) 쉘로 모델링하였지만, 요 소의 크기가 작아서 차량이나 열차 같은 다수의 에너지 흡수 부재가 포함된 구조물에서는 해석시간의 문제로 활용이 불가 능하다. 또한, Hage 등[4]은 단층 (one-layer) 쉘 요소에 순차적 으로 두께를 줄이는 방법을 이용하였지만, 알루미늄 판재 바 깥에 복합재가 붙은 하이브리드(Hybrid) 형식으로 복합재 트리 거의 영향이 적고 알루미늄 거동에 가까운 결과를 보였다. 이 렇듯 복합재료로만 구성되고, 최종적으로 충돌모델로 활용 가 능한 트리거 모델에 대한 연구는 부족한 실정이다.

본 연구에서는 일방향 케블라/에폭시로 제작된 복합소재 튜 브에 대한 트리거 모델링과 해석 기법을 확립하고 이를 시험 과 비교를 통해 검증하였다. 이를 위해 상용 외연적 유한요소 코드인 LS-DYNA를 사용하였고, 2D 쉘 유한요소 모델에 Chang-Chang 파손 이론을 적용하여 에너지 흡수 특성을 해석 적 방법으로 확인하였다.

\section{2. 시험적 연구}

\section{1 복합소재 시험편}

\subsection{1 물성치 및 제작과정}

본 연구에서는 일방향 케블라/에폭시 프리프레그 (케블라 섬유 - K49, Dupont, USA)와 R1222 (HFG, Co.) 수지를 이 용하여 복합소재 튜브를 제작하였다. 복합소재 튜브에 적용 된 소재의 기본 물성치는 Table 1 과 같다[5].

원형튜브의 제작과정은 먼저 일방향 프리프레그를 직경 $30 \mathrm{~mm}$ 의 원형 금속파이프에 렙퍼(wrapper 또는 wrapping machine)를 이용하여 감고, 이를 오븐에서 성형하여 $1 \mathrm{~m}$ 길이의 복합소재 원형파이프를 제작하였다. 성형조건은 분당 $3.5^{\circ} \mathrm{C}$ 로 $135^{\circ} \mathrm{C}$ 까 지 온도를 올리고 $135^{\circ} \mathrm{C}$ 에서 1 시간 30 분 유지한 후 1 시간에 걸쳐 온도를 상온까지 내렸다. $1 \mathrm{~m}$ 의 길이로 제작된 튜브는 다이아몬드 와이어를 이용하여 원하는 크기로 절단하였다.
Table 1 Mechanical properties

\begin{tabular}{c|c|c}
\hline \hline Properties & Symbol & Value \\
\hline \multirow{2}{*}{ Elastic modulus (GPa) } & $E_{11}$ & $83.9(4.04)$ \\
\cline { 2 - 3 } & $E_{22}$ & 6.07 \\
\hline Shear modulus (GPa) & $G_{12}$ & $5.91(0.27)$ \\
\hline \multirow{2}{*}{ Tensile strength (MPa) } & $X_{T}$ & $1232(57.4)$ \\
\cline { 2 - 3 } & $Y_{T}$ & 24.99 \\
\hline \multirow{2}{*}{ Compressive strength (MPa) } & $X_{C}$ & $182.4(39.8)$ \\
\cline { 2 - 3 } & $Y_{C}$ & 91.2 \\
\hline Shear strength (MPa) & $S$ & $77.8(2.50)$ \\
\hline ILSS (MPa) & $Q$ & $63.2(0.66)$ \\
\hline \hline
\end{tabular}

( ): standard deviations

\subsection{2 치수 및 형상}

복합소재 튜브의 길이방향을 $0^{\circ}$, 원주방향을 $90^{\circ}$ 로 섬유 방향을 설정하였다. 케블라/에폭시 튜브의 적층구조는 [90/0 $]_{11}$ 으로 두께는 $2.2 \mathrm{~mm}$ 이다. 튜브의 한쪽 끝단에는 $45^{\circ}$ 베벨트 리거 가공을 하였고 시편의 치수와 형상은 Fig. 1 과 같다.

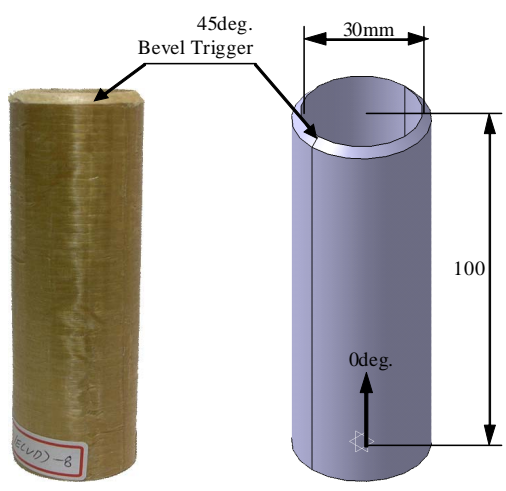

(a) Kevlar/Epoxy Tube

(b) 3D Model

Fig. 1 Dimension and shape of composite circular tubes.

\section{2 시험 절차}

본 연구에서 수행된 준정적 압축시험은 $100 \mathrm{kN}$ 용량의 만 능시험기(Fig. 2(a))를 이용하였다. 원형튜브를 압축하기 위한 상, 하 하중판 (load platens)은 시험 전에 평형을 확인하였 다. 시험 시 하중과 크로스헤드의 변위를 기록하였으며 각 5 개의 튜브를 $10 \mathrm{~mm} / \mathrm{min}$ 의 속도로 시험하였다.

\section{3. 유한요소해석}

\section{1 유한요소모델링}

유한 요소 해석은 외연적 코드인 LS-DYNA 9.71을 이용하 였다. 해석 시간을 줄이기 위해 모든 요소를 4절점 under integrated Belyrschko-Tsay 쉘로 사용하였고 요소의 크기는 복합재 


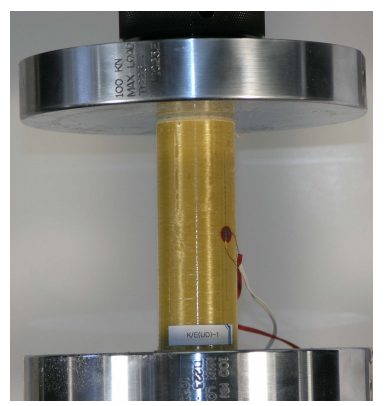

(a) Test

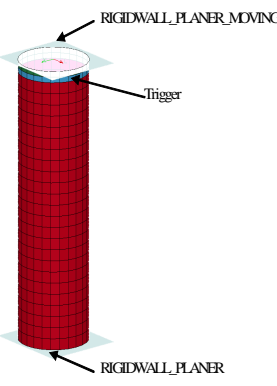

(b) Numerical model
Fig. 2 Finite element modeling of the axial crushing of the composite tube.

두께의 2배 크기로 모델링하였다. Under integrated 셀의 non- physical, 제로-에너지 모드 (zero-energy mode)를 억제하기 위해서 FlanganBelyschko 강성 이론[6]을 적용하였다.

유한요소 모델링상에서 튜브의 압괴는 Fig. 2(b)와 같이 LS-DYNA에서 제공하는 "RIGIDWALL_PLANER_MOVING" 옵션을 사용하였다. 튜브의 하단에는 "RIGIDWALL_PLA NER"로 바닥을 생성하였으며, 하중판과 튜브 사이의 마찰계 수는 0.3 을 사용하였다[4]. 압괴과정 중 좌굴에 의한 튜브벽 면 간의 접촉을 고려하기 위해 "CONTACT_AUTOM ATIC_ SINGLE_SURFACE” 옵션을 사용하였으며 튜브 바닥은 회전 구속 없이 $\mathrm{X}, \mathrm{Y}$ 변위만 구속시켰다.

\section{2 트리거 모델}

최대 하중을 줄이고 안정적인 압괴 진행을 위해 트리거의 모델링은 필수적이다. 일반적으로 Fig. 1 과 같은 형태로 튜브 의 끝단을 가공하여 트리거를 부과한다. 이러한 트리거의 단 면형상은 Fig. 3(a)와 같다. 이러한 형상은 3차원 쏠리드 요 소 (solid element)를 이용해서 모델링해야 정확히 구현이 가 능하다. 그러나, 쏠리드 요소를 적용할 경우에는 요소수 증가 에 따른 해석시간의 문제로 단품 해석시에만 활용이 가능하 다. 따라서 차량 전체의 모델링시 복합소재 튜브와 같은 충 격흡수부재는 단순한 부품의 일부로 쏠리드 요소를 이용한 정밀한 모델링은 한계가 있어 3차원 쉘 요소를 이용하여 모 델링하는 것이 일반적이다.

그러나, 쉘 요소를 이용하여 Fig. 3(a)의 $45^{\circ}$ 베벨 트리거 를 구현하는 것은 불가능하다. 따라서, 본 연구에서는 요소수 를 크게 증가시키지 않는 범위 내에서 Fig. 3(b) Fig. 3(d) 와 같은 트리거의 기준 모델(base model)을 만들고, 그 기준 모델의 두께, $\mathrm{t}$ 와 강도를 변수로 하여 실제와 가장 유사한 압축거동을 보이는 트리거 형상을 도출하고자 한다.

트리거 타입 1 은 해석 모델의 요소 크기에 맞춰 $4.4 \mathrm{~mm}$ 상단 트리거가 만들어진 모델이며, 타입 2, 3은 타입 1의 상 단트리거를 $1 / 2$ 크기로 분할한 것이다. 타입 3 는 두께는 변화

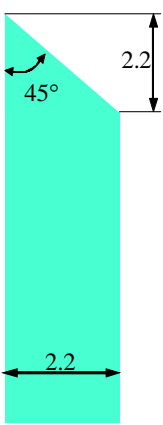

(a) Real

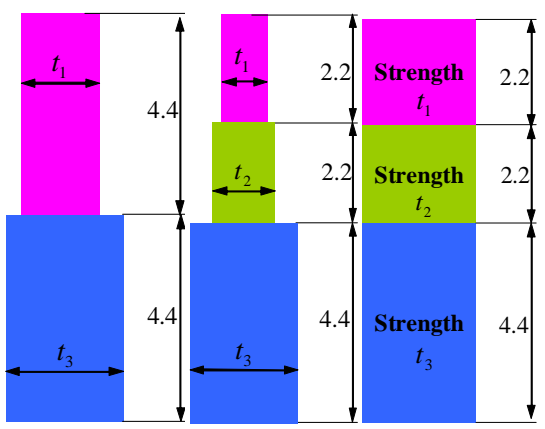

(b) Type 1

(c) Type 2

(d) Type 3
Table 2 Design parameters for the trigger modelling

\begin{tabular}{|c|c|c|c|c|}
\hline & & $\mathrm{t}_{1}$ & $\mathrm{t}_{2}$ & $\mathrm{t}_{3}$ \\
\hline \multirow{3}{*}{$\begin{array}{c}\text { Type } 1 \\
\text { (thickness) }\end{array}$} & a & $25 \%$ & - & \multirow{15}{*}{$\begin{array}{c}100 \% \\
(2.2 \mathrm{~mm})\end{array}$} \\
\hline & $\mathrm{b}$ & $50 \%$ & - & \\
\hline & C & $75 \%$ & - & \\
\hline \multirow{6}{*}{$\begin{array}{c}\text { Type } 2 \\
\text { (thickness) }\end{array}$} & $\mathrm{a}$ & $25 \%$ & $50 \%$ & \\
\hline & $\mathrm{b}$ & $25 \%$ & $75 \%$ & \\
\hline & C & $25 \%$ & $100 \%$ & \\
\hline & d & $50 \%$ & $75 \%$ & \\
\hline & e & $50 \%$ & $100 \%$ & \\
\hline & $\mathrm{f}$ & $75 \%$ & $100 \%$ & \\
\hline \multirow{6}{*}{$\begin{array}{c}\text { Type } 3 \\
\text { (strength) }\end{array}$} & $\mathrm{a}$ & $25 \%$ & $50 \%$ & \\
\hline & $\mathrm{b}$ & $25 \%$ & $75 \%$ & \\
\hline & C & $25 \%$ & $100 \%$ & \\
\hline & $\mathrm{d}$ & $50 \%$ & $75 \%$ & \\
\hline & $\mathrm{e}$ & $50 \%$ & $100 \%$ & \\
\hline & $\mathrm{f}$ & $75 \%$ & $100 \%$ & \\
\hline
\end{tabular}

시키지 않고 강도의 변화를 준 모델이다. $\mathrm{t} 1$ 은 상단 트리거, t2는 하단트리거로 Table 2에서 튜브의 기본 두께, 강도를 나 타내는 $\mathrm{t} 3$ 와의 비율로 표시하였다.

\section{3 파손이론}

복합재 모델은 Chang-Chang 파손식[7] [8]을 적용한 MAT054 “MAT_ENHANCED_COMPOSITE_DAMAGE”를 이용하였다. Chang-Chang 파손 이론은 Hashin 파손식[9]의 수정된 형태 로 전단응력-변형률 거동을 포함하며, 연속적으로 단층의 파 손이 발생할 경우 적층판의 점진적인 파손거동을 묘사하기 위해 파손 후 강도저하 기법이 적용되어 있다. 이 기법에서 단층의 섬유파단과 수지전단파단이 동시 또는 개별적으로 발 생할 경우 횡방향 강성 및 마이너 푸아송비가 0 으로 저하되 며, 섬유방향 강성 및 전단강성은 Weibull 분포를 따른다. 수 지의 인장 또는 압축파단이 먼저 발생할 경우, 횡방향 강성 및 마이너 푸아송비가 0 으로 저하되며, 섬유방향 강성 및 전 단강성은 변화하지 않는다 [10]. 각 파손모드별 파손식은 식 (1) - (4)와 같다. 
섬유의 인장 모드 (섬유 파단)

$\sigma_{11}>0$ 이면 $e_{f}^{2}=\left(\frac{\sigma_{11}}{X_{T}}\right)^{2}+\beta\left(\frac{\sigma_{12}}{S}\right)^{2}-1$

$\begin{cases}\geq 0 & \text { failed } \\ <0 & \text { elastic }\end{cases}$

$E_{11}=E_{22}=G_{12}=\nu_{21}=\nu_{12}=0$

섬유의 압축 모드 (섬유 좌굴 및 킨킹)

$\sigma_{11}<0$ 이면 $e_{c}^{2}=\left(\frac{\sigma_{11}}{X_{C}}\right)^{2}-1$

$\begin{cases}\geq 0 & \text { failed } \\ <0 & \text { elastic }\end{cases}$

$E_{11}=\nu_{21}=\nu_{12}=0$

수지의 인장 모드 (횡방향 인장 및 전단에 대한 수지 균열) $\sigma_{22}>0$ 이면 $e_{m}^{2}=\left(\frac{\sigma_{22}}{Y_{T}}\right)^{2}+\left(\frac{\sigma_{12}}{S}\right)^{2}-1$

$\{\geq 0$ failed

$\{<0$ elastic

$E_{22}=\nu_{21}=0 \rightarrow G_{12}=0$

수지의 압축 모드 (횡방향 압축 및 전단에 대한 수지 균열) $\sigma_{22}<0$ 이면

$e_{d}^{2}=\left(\frac{\sigma_{22}}{2 S}\right)^{2}+\left[\left(\frac{Y_{C}}{2 S}\right)^{2}-1\right] \frac{\sigma_{22}}{Y_{C}}+\left(\frac{\sigma_{12}}{S}\right)^{2}-1$

$\begin{cases}\geq 0 & \text { failed } \\ <0 & \text { elastic }\end{cases}$

$E_{22}=\nu_{21}=\nu_{12}=0 \rightarrow G_{12}=0$

여기서 $\sigma_{11}$ 는 섬유 방향의 응력, $\sigma_{22}$ 는 섬유 직교 방향의 응력, $\sigma_{12}$ 는 a-b 평면상의 전단응력, $X_{T}$ 는 섬유방향의 인장 강도, $Y_{T}$ 는 섬유 직교 방향의 인장강도이다. $X_{C}$ 는 섬유방 향의 압축강도, $Y_{C}$ 는 섬유 직교 방향의 압축강도이며, $S$ 는 전단강도이다.

\section{4. 시험 및 수치해석 결과}

하중-변위 곡선에서 아래쪽의 면적은 에너지 흡수량 $E_{a b s}$ 로 식(5)에 의해서 계산된다. 최대하중은 하중-변위 곡선의 선형구 간의 끝을 가리키고 평균하중은 최대하중 이후 일정한 하중을 보이는 값을 말한다. 압괴길이는 튜브의 접촉이후 하중이 급격 히 증가하기 직전까지를 의미한다. 흡수에너지를 표현하는 방식 은 두 가지가 있는데 식(6)으로 흡수에너지를 흡수부재의 전체 의 무게로 나누는 방법, $E_{s t}$ 와 식 (7)로 흡수부재중 흡수에 기
여한 무게만을 고려하는 방법, $E_{s p}$ 가 있다. 압괴하중효율 (crush force efficiency), $C F_{\text {eff }}$ 는 초기최대하중과 평균압괴하중의 비율 로 표현한다. 흡수길이효율 (stroke efficiency), $S_{e f f}$ 는 튜브의 초기길이와 에너지 흡수에 기여한 길이의 비율로 표현된다.

$$
\begin{aligned}
& E_{a b s}=\int_{0}^{L_{C}} P d \delta \\
& E_{s t}=\frac{E_{a b s}}{m_{\text {total }}}=\frac{\int_{0}^{L_{C}} P d \delta}{m_{\text {total }}} \\
& E_{s p}=\frac{E_{a b s}}{m_{\text {total }} \frac{L_{c}}{L_{t}}}=\frac{\int_{0}^{L_{C}} P d \delta}{m_{\text {total }} \frac{L_{c}}{L_{t}}}
\end{aligned}
$$

\section{1 시험 결과}

축방향 압축시험은 일방향 케블라/에폭시 튜브에 대해 각각 5 회 수행되었다. Table 3은 시험 후 얻은 에너지 흡수특성을 나타낸 것이다.

Table 3 Summary of energy absoption capabilities of the unidirectional Kevlar/epoxy tub

\begin{tabular}{c|c|c|c|c|c|c}
\hline Specimen & K/E-1 & K/E-2 & K/E-3 & K/E-4 & K/E-5 & Average \\
\hline $\begin{array}{c}\text { Length(mm) } \\
\begin{array}{c}\text { Crushed } \\
\text { Length(mm) }\end{array}\end{array}$ & 100.42 & 100.44 & 100.65 & 100.47 & 100.46 & $\begin{array}{c}100.49 \\
(0.08)\end{array}$ \\
\hline$E_{s t}(\mathrm{~kJ} / \mathrm{kg})$ & 42.55 & 44.07 & 40.38 & 44.97 & 43.79 & $\begin{array}{c}43.15 \\
(1.59)\end{array}$ \\
\hline$E_{s p}(\mathrm{~kJ} / \mathrm{kg})$ & 52.93 & 55.69 & 49.42 & 57.69 & 54.74 & $\begin{array}{c}54.09 \\
(2.79)\end{array}$ \\
\hline $\begin{array}{c}\text { Peak } \\
\text { Load(kN) }\end{array}$ & 17.73 & 16.88 & 17.95 & 17.42 & 17.82 & $\begin{array}{c}17.56 \\
(0.38)\end{array}$ \\
\hline $\begin{array}{c}\text { Mean } \\
\text { Load(kN) }\end{array}$ & 12.75 & 12.94 & 12.04 & 13.36 & 12.83 & $\begin{array}{c}12.78 \\
(0.43)\end{array}$ \\
\hline Weight(g) & 24.21 & 23.36 & 24.53 & 23.38 & 23.57 & $\begin{array}{c}23.79 \\
(0.49)\end{array}$ \\
\hline \hline
\end{tabular}

( ): standard deviations

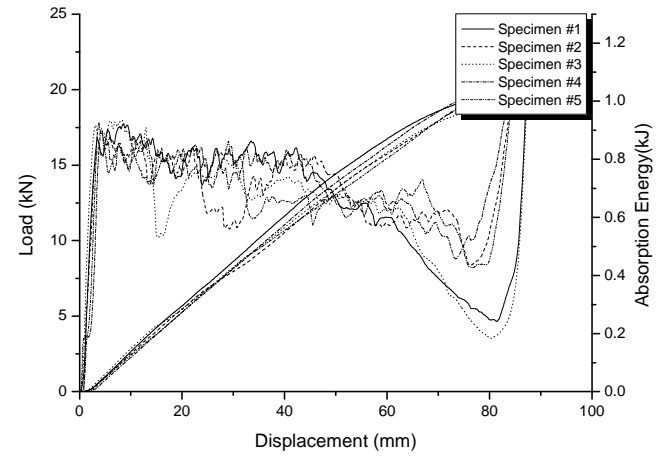

Fig. 4 Load-cnushed displacement curves of the unidirectional Kevlar/ epoxy tube. 
Table 4 Comparison of energy absoption capability between test and simulation under three different trigger types

\begin{tabular}{|c|c|c|c|c|c|c|c|c|c|c|c|c|c|c|c|c|}
\hline & \multirow{2}{*}{$\begin{array}{c}\text { Test } \\
\text { average }\end{array}$} & \multicolumn{3}{|c|}{ Type 1} & \multicolumn{6}{|c|}{ Type 2} & \multicolumn{6}{|c|}{ Type 3} \\
\hline & & $\mathbf{a}$ & $\mathrm{b}$ & $\mathrm{c}$ & $\mathrm{a}$ & $\mathrm{b}$ & c & $\mathrm{d}$ & $\mathrm{e}$ & $f$ & $\mathrm{a}$ & $\mathrm{b}$ & $\mathrm{C}$ & $\mathrm{d}$ & $\mathrm{e}$ & $\mathrm{f}$ \\
\hline $\begin{array}{c}\text { Crushed } \\
\text { Length(mm) }\end{array}$ & 80.2 & $\begin{array}{l}84.9 \\
(5.8)\end{array}$ & - & $\begin{array}{l}93.9 \\
(17)\end{array}$ & $\begin{array}{l}85.7 \\
(6.8)\end{array}$ & $\begin{array}{l}79.1 \\
(1.3)\end{array}$ & $\begin{array}{c}83.6 \\
(4.24)\end{array}$ & $\begin{array}{l}81.7 \\
(1.8)\end{array}$ & $\begin{array}{c}88.5 \\
(10.3)\end{array}$ & $\begin{array}{c}90.3 \\
(12.5)\end{array}$ & $\begin{array}{l}80.7 \\
(0.6)\end{array}$ & $\begin{array}{l}75.5 \\
(5.8)\end{array}$ & $\begin{array}{l}83.1 \\
(3.6)\end{array}$ & $\begin{array}{l}84.3 \\
(5.1)\end{array}$ & $\begin{array}{l}85.9 \\
(7.1)\end{array}$ & $\begin{array}{l}85.3 \\
(6.3)\end{array}$ \\
\hline$E_{s t}(\mathrm{~kJ} / \mathrm{kg})$ & 43.1 & $\begin{array}{l}43.8 \\
(1.6)\end{array}$ & - & $\begin{array}{c}52.5 \\
(21.8)\end{array}$ & $\begin{array}{l}41.0 \\
(4.8)\end{array}$ & $\begin{array}{c}37.2 \\
(13.6)\end{array}$ & $\begin{array}{l}43.8 \\
(1.6)\end{array}$ & $\begin{array}{l}42.0 \\
(2.5)\end{array}$ & $\begin{array}{l}39.9 \\
(7.4)\end{array}$ & $\begin{array}{c}48.1 \\
(11.6)\end{array}$ & $\begin{array}{l}43.1 \\
(0)\end{array}$ & $\begin{array}{c}29.9 \\
(30.6)\end{array}$ & $\begin{array}{c}27.1 \\
(37.1)\end{array}$ & $\begin{array}{l}41.6 \\
(3.4)\end{array}$ & $\begin{array}{l}41.8 \\
(3.0)\end{array}$ & $\begin{array}{l}44.2 \\
(2.5)\end{array}$ \\
\hline$E_{s p}(\mathrm{~kJ} / \mathrm{kg})$ & 54.0 & $\begin{array}{l}51.6 \\
(4.4)\end{array}$ & - & $\begin{array}{l}55.9 \\
(3.5)\end{array}$ & $\begin{array}{c}47.8 \\
(11.4)\end{array}$ & $\begin{array}{c}47.0 \\
(12.9)\end{array}$ & $\begin{array}{l}54.6 \\
(1.1)\end{array}$ & $\begin{array}{l}51.4 \\
(4.8)\end{array}$ & $\begin{array}{c}45.1 \\
(16.4)\end{array}$ & $\begin{array}{l}53.3 \\
(1.3)\end{array}$ & $\begin{array}{l}53.3 \\
(1.3)\end{array}$ & $\begin{array}{c}39.6 \\
(26.6)\end{array}$ & $\begin{array}{c}32.6 \\
(39.6)\end{array}$ & $\begin{array}{l}49.3 \\
(8.7)\end{array}$ & $\begin{array}{c}48.6 \\
(10.0)\end{array}$ & $\begin{array}{l}51.8 \\
(4.0)\end{array}$ \\
\hline $\begin{array}{c}\text { Peak Load } \\
(\mathrm{kN})\end{array}$ & 17.5 & $\begin{array}{l}18.7 \\
(6.8)\end{array}$ & $\begin{array}{c}21.1 \\
(20.5)\end{array}$ & $\begin{array}{c}19.5 \\
(11.4)\end{array}$ & $\begin{array}{c}20.7 \\
(18.2)\end{array}$ & $\begin{array}{l}19.0 \\
(8.5)\end{array}$ & $\begin{array}{c}18.6 \\
(6.29)\end{array}$ & $\begin{array}{c}21.5 \\
(22.8)\end{array}$ & $\begin{array}{c}22.5 \\
(28.5)\end{array}$ & $\begin{array}{c}19.9 \\
(13.7)\end{array}$ & $\begin{array}{c}21.9 \\
(25.1)\end{array}$ & $\begin{array}{c}21.1 \\
(20.5)\end{array}$ & $\begin{array}{c}21.7 \\
(24.0)\end{array}$ & $\begin{array}{c}21.9 \\
(25.1)\end{array}$ & $\begin{array}{c}23.0 \\
(31.4)\end{array}$ & $\begin{array}{c}21.3 \\
(21.7)\end{array}$ \\
\hline $\begin{array}{c}\text { Mean Load } \\
(\mathrm{kN})\end{array}$ & 12.7 & $\begin{array}{l}12.6 \\
(0.7)\end{array}$ & - & $\begin{array}{l}13.5 \\
(6.3)\end{array}$ & $\begin{array}{c}11.4 \\
(10.2)\end{array}$ & $\begin{array}{c}11.3 \\
(11.0)\end{array}$ & $\begin{array}{c}13.1 \\
(3.15)\end{array}$ & $\begin{array}{l}12.5 \\
(1.5)\end{array}$ & $\begin{array}{c}11.0 \\
(13.3)\end{array}$ & $\begin{array}{l}13.0 \\
(2.3)\end{array}$ & $\begin{array}{l}13.0 \\
(2.3)\end{array}$ & $\begin{array}{c}9.68 \\
(23.7)\end{array}$ & $\begin{array}{c}7.97 \\
(37.2)\end{array}$ & $\begin{array}{l}12.0 \\
(5.5)\end{array}$ & $\begin{array}{l}11.8 \\
(7.0)\end{array}$ & $\begin{array}{l}12.6 \\
(0.7)\end{array}$ \\
\hline
\end{tabular}

( ): error(\%)

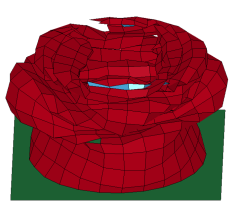

(a) Type 1a

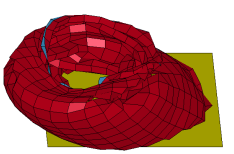

(d) Type 2a

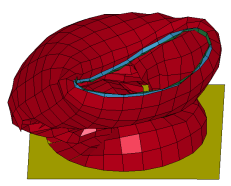

(g) Type 2d

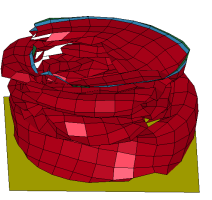

(j) Type 3a

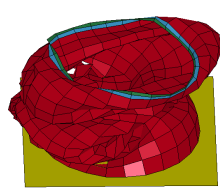

(m) Type 3d

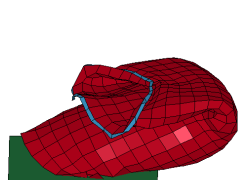

(b) Type 1b

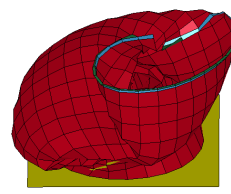

(e) Type 2b

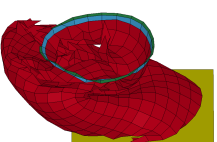

(h) Type $2 \mathrm{e}$

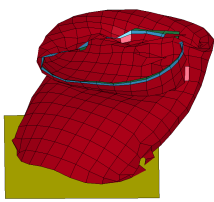

(k) Type 3b

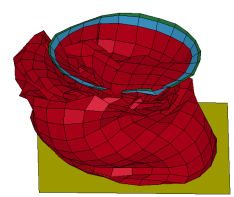

(n) Type $3 \mathrm{e}$

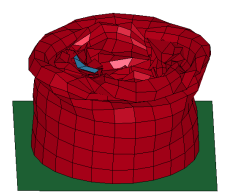

(c) Type 1c

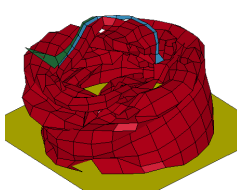

(f) Type 2c

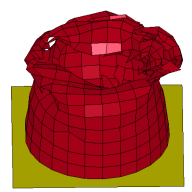

(i) Type $2 f$

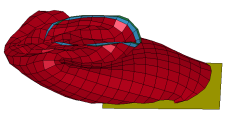

(l) Type 3c

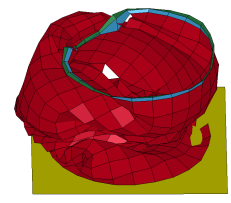

(o) Type 3f
Fig. 5 Cnushed shapes after axial displacement of $80 \mathrm{~mm}$.
일방향 케블라/에폭시 튜브의 압축시험을 통해 얻은 하중변위 선도는 Fig. 4와 같다. 트리거는 압괴 변위 3 4.2mm에서 벌림 (splaying) 모드로 압괴되고, 3 8mm 사이에서 각각의 평 균하중에 도달하며 이때 최대하중의 평균치는 $17.56 \mathrm{kN}$ 이다. 최 대하중이 지나고 $60 \mathrm{~mm}$ 부근에서 1,3 시편, $70 \mathrm{~mm}$ 부근에서 2, 4, 5번 시편이 좌굴 (global buckling) 모드로 파단이 진행되 었다. 압괴길이 $80 \mathrm{~mm}$ 부근에서 튜브 벽면의 접힘부가 쌓여서 압괴가 진행되지 않고 하중이 급격히 증가하게 된다. 최대 압 괴길이까지 튜브가 흡수한 에너지량은 평균 $1,025 \mathrm{~J}$ 이다.

\section{2 수치해석 결과}

4.2.1 트리거 형상별 압축모드 및 하중-변위선도

트리거 모델에 대한 압괴거동은 두 가지 관점에서 살펴보 았다. 첫 번째는 압괴 초기단계에서 좌굴의 발생 여부를 살펴 보았고, 두 번째로는 최대하중을 시험결과와 비교하였다. 압 괴 초기단계에서 좌굴이 발생하는 경우는 에너지가 흡수되지 못함을 뜻하고, 최대 하중이 높은 것은 트리거의 강성이 높아 탄성영역, 트리거 붕괴영역의 거동이 일치하지 않으며 좌굴 발생의 원인이 된다. Fig. 5는 압괴길이 $80 \mathrm{~mm}$ 에서의 형상을 보여주고 있다. 총 15 개의 트리거 모델 중 타입 1a, 1c, 2c, $2 \mathrm{f}, 3 \mathrm{a}$ 가 초기좌굴 없이 안정적인 압괴 거동을 보였다.

Fig. 6의 하중-변위선도에서 좌굴이 발생한 트리거의 경우 하중이 급격하게 감소하는 것을 알 수 있다.

\subsection{2 트리거 형상별 에너지 흡수특성}

Table 4는 트리거 형상에 따른 에너지 흡수 특성을 시험결 과와 비교한 것이다. 최대압괴길이는 변위 $70 ~ 90 \mathrm{~mm}$ 에서 하 중이 감소 후 증가하는 위치를 선정하였으며, 이 값을 이용하 여 $E_{s t}, E_{s p}$, 평균하중을 계산하였다. 다만 타입 $1 \mathrm{~b}$ 트리거 모델은 압괴길이 $35 \mathrm{~mm}$ 에서 좌굴이 발생한 후 점진적으로 하 중이 증가하여 최대압괴길이의 파악이 어려워 제외하였다. 


\section{5. 결과 분석 및 고찰}

시험과의 비교 시 에너지 흡수특성과 하중값의 오차가 $10 \%$ 보다 작은 트리거 타입은 1a와 2c 이다. Fig. 7은 시험 결과와 트리거 타입은 $1 \mathrm{a}$ 와 2c의 하중-변위선도를 비교한 것 이다.

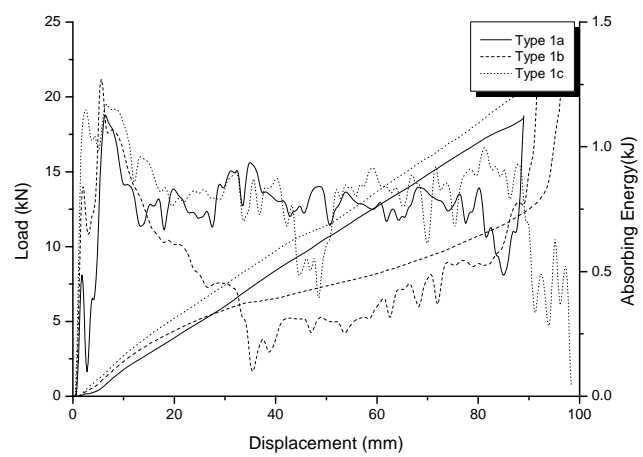

(a) Trigger type 1

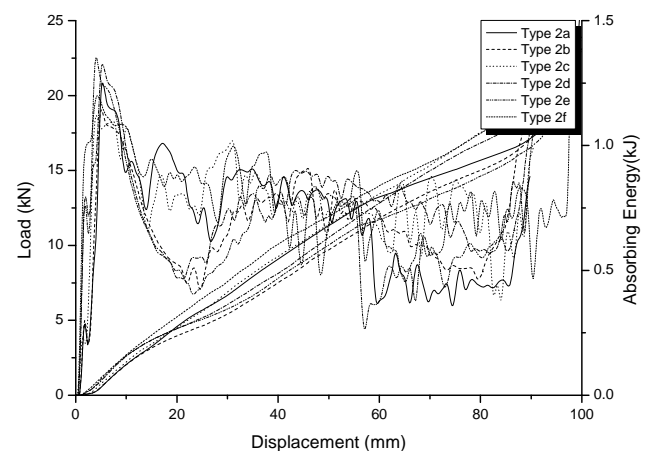

(b) Trigger type 2

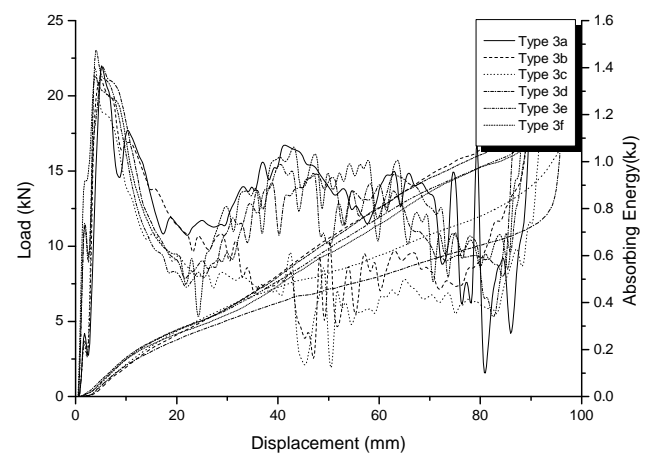

(c) Trigger type 3

Fig. 6 Load-displacement curves for different trigger types.
타입 $1 \mathrm{a}$ 는 초기 선형구간의 기울기는 유사하지만 트리거가 파단되어 하중이 감소하는 현상이 발생한다. 최대하중 후 압괴 진행과정에서 시험치와 유사한 거동을 보였으며 불안정한 거 동 없이, 순차적인 접힘으로 $84.9 \mathrm{~mm}$ 에서 최대 압괴가 되었다. 타입 2c는 초기 선형구간의 기울기와 최대하중이 상당히 유사 하며, 최대하중 후 압괴 진행과정에서도 시험치와 유사한 거동 을 보였다. 약 $80 \mathrm{~mm}$ 압축지점에서 하중이 감소하기 시작하는 데, 이때 불안정 압괴가 발생하였다. 그 후 최대압괴 시점이 $83.6 \mathrm{~mm}$ 로 시험의 평균치인 $80.22 \mathrm{~mm}$ 과는 다소 차이가 있다.

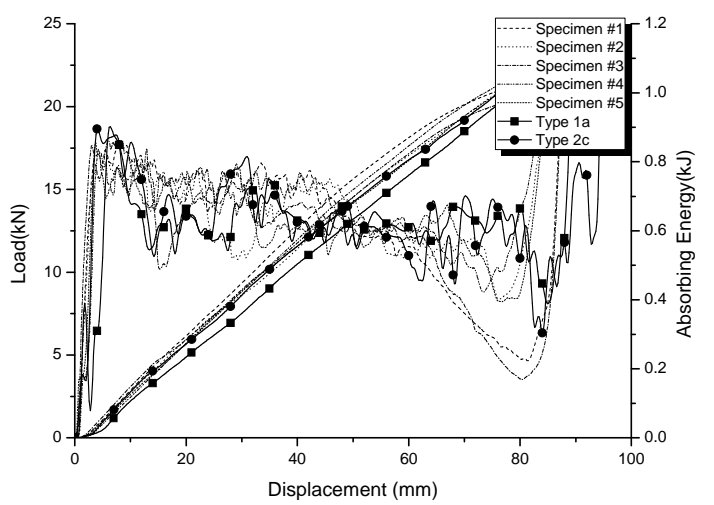

Fig. 7 Comparison of experimental and numerical load-cnushed displacement curves.

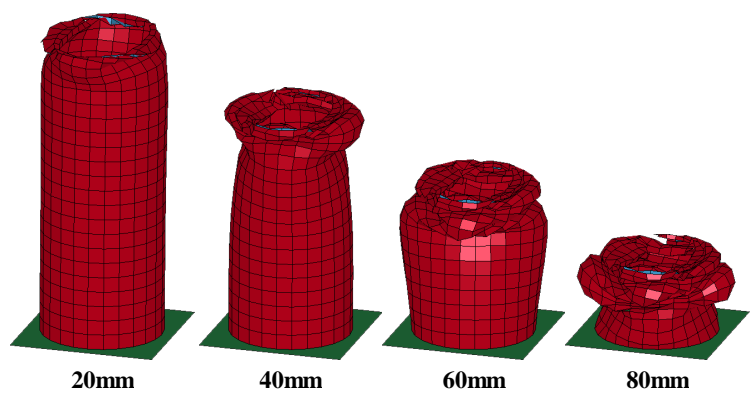

(a) Trigger Type 1a

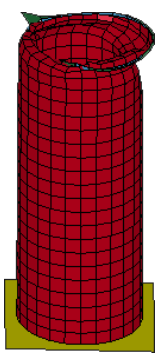

$20 \mathrm{~mm}$

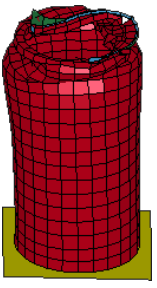

$40 \mathrm{~mm}$

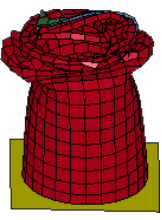

$60 \mathrm{~mm}$

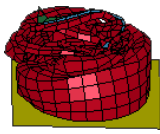

$80 \mathrm{~mm}$
Fig. 8 Compression process of numerical model. 


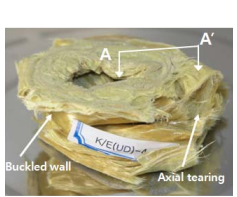

(a) Experiment

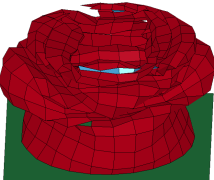

(c) Type 1a

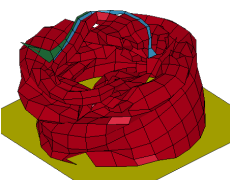

(c) Type 2c
Fig. 9 Final crush shapes of the unidirectional Kevlar/epoxy.

해석과 시험의 결과 차이는 이전에 언급한 트리거부 모델링 과 실제의 차이, 시험편의 불균일성 (시험편의 경우 원형 금속 튜브에 복합소재를 말아서 제작하였기 때문에 원주방향으로 시편의 두께가 균일하지 않다) 등에 기인한 것으로 판단된다.

일방향 케블라/에폭시 튜브 해석모델의 압괴과정은 Fig. 8(a), (b)와 같이 트리거 타입 $1 \mathrm{a}, 2 \mathrm{c}$ 모두 점진적인 접힘 (Progressive Folding)에 의해 압괴가 진행되었다. 타입 $1 \mathrm{a}$ 는 시편 전체가 점진적인 접힘에 의해 압괴되었으며, 타입 2c는 $80 \mathrm{~mm}$ 압괴 후 좌굴이 발생하였다. Fig. 9(a) Fig. 9(c)는 최종 압괴상태에서 시편 형상을 비교하였다. 타입 2c에서 좌 굴발생이 시험보다 지연되어 전체 압괴 형상은 다소 차이가 있지만, 트리거 부근의 압괴 모습은 유사하게 모사되었다. Fig. 10(a), (b), (c)에서는 단면에 의한 순차적인 접힘을 보여 주고 있다.

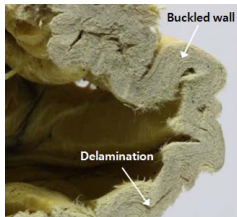

(a) Expeniment

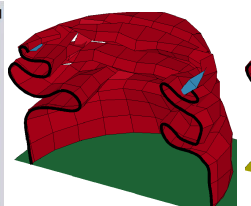

(b) Type 1a

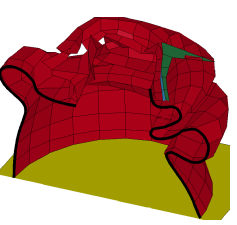

(b) Type 2c
Fig. 10 Sectional view of the final crush shapes of the unidirectional Kevlar/epoxy.

\section{6. 결 론}

본 연구에서는 일방향 케블라/에폭시 튜브에 다양한 트리 거 모델을 적용하여 해석을 수행하였으며, 시험 결과와 비교 하였다. 결과로부터 다음과 같은 결론을 얻었다.

- 트리거의 두께를 조절하여 얻은 결과로부터 상단트리거가 하단트리거의 25\% 두께 (타입 1a, 2c)일 때, 가장 유사한 에너지흡수 특성 및 하중값을 보였다.

- 강도를 조절한 트리거의 경우, 타입 3a를 제외하고 모두 좌굴이 발생했으며, 최대하중이 매우 높다.

- 따라서, 타입 1a, 2c의 트리거 모델은 일방향 케블라/에폭시 복합재 튜브의 트리거로 적합한 것으로 판단된다.
참고문헌

1) C. Kindervater, "The Crashworthiness of Composite Aerospace Structures," Workshop, the Crashworthiness of Composite Transportation Structures, TRL, Crowthorne, 3rd October, 2002.

2) M. Wacker and M. Hormann, "Simulation of the Crash Performance of Crash Boxes based on Advanced Thermoplastic Composite,” 22nd CAD-FEM Users’ Meeting 2004 International Congress on FEM Technology with ANSYS CFX \& ICEM CFD Conference, 2004, Internati onal Congress Center Dresden, Germany.

3) Jiancheng Huang, Xinwei Wang, "Numerical and experimental investigations on the axial crushing response of composite tubes,” Composite Structures, Vol. 91, 2009, pp. 222-228.

4) H El-Hage, $P$ K Mallick, and N Zamani, "Numerical modelling of quasi-static axial crush of square aluminum-composite hybrid tubes," International Journal of Crashworthiness, Vol. 9, Issue 6, January, 2004, pp. 653-664

5) 김정석, 윤혁진, 이호선, 최경훈, “강화 섬유에 따른 준 정적 하중하에서 복합소재 원형튜브의 에너지 흡수특성 평가 연구,” 한국복합재료학회, 제22권, 제6호, 2009, pp. 32-38.

6) D.P. Flanagan, T. Belytschko, "A uniform strain hexahedron and quadrilateral with orthogonal ho urglass control," Int. J. Numer. Methods Eng, 17, 1981, pp. 679-706.

7) Chang, F.K., and Chang, K.Y., "Post-Failure Analysis of Bolted Composite Joints in Tension or Shear-Out Mode Failure,” J. of Composite Materials, 21, 1987, pp. 809-833

8) Chang, F.K., and Chang, K.Y., "A Progressive Damage Model for Laminated Composites Containing Stress Concentration," J. of Composite Materials, 21, 1987, pp. 834-855

9) Hanshin, Z, "Failure Criteria for Unidirectional Fiber Composites," Journal of Applied Mechanic s, 47, 1980, pp. 329.

10) Livermore Software Technology Corporation, "L S-DYNA user's manual (nonlinear dynamic analysis of structures in three dimensions)," 1997.

12) B.D. Davidson and V. Sundararaman, "A single leg bending test for interfacial fracture toughness determination," Int J Fract. Vol. 78, 1996, pp. 193-210.

13) "Standard Test Method for Mode I Fatigue Delamination Growth Onset of Unidirectional Fiber-Reinforced Polymer Matrix Composites,” ASTM STP D 6115.

14) "Standard Test Method for Measurement of Fatigue Crack Growth Rates,” ASTM STP E 647. 